\title{
Effects of Solution pH and Seed Material on MAP Crystallization
}

\author{
Ping Tang*, Huan-lin Ma \\ College of Environment and Material Engineering, Hangzhou Dianzi University, Hangzhou, China
}

\author{
Email address: \\ tangping@hdu.edu.cn (Ping Tang) \\ ${ }^{*}$ Corresponding author
}

\section{To cite this article:}

Ping Tang, Huan-lin Ma. Effects of Solution $\mathrm{pH}$ and Seed Material on MAP Crystallization. International Journal of Environmental Protection and Policy. Vol. 4, No. 6, 2016, pp. 171-177. doi: 10.11648/j.ijepp.20160406.13

Received: October 26, 2016; Accepted: December 22, 2016; Published: December 28, 2016

\begin{abstract}
Experimental results revealed that solution $\mathrm{pH}$ was one of the most important factor which effected not only phosphorus recovery percentage but also phosphorus recovery rate during the struvite forming process. Introduction of seed materials increased the phosphorus recovery percentage to an extent and optimum seed particle range and adding amount were 70-140 mesh and $0.5 \mathrm{~g}$ (solution $\mathrm{pH}=8.5$ ). The one-stage seed addition worked better than multi-stage addition and phosphorus recovery percentage rose with increasing initial seed dosing. Seed addition speeded the phosphorus recovery rate to some extent on the whole.
\end{abstract}

Keywords: pH, Seed, Phosphorus Recovery Percentage, Struvite

\section{Introduction}

Phosphorus is an important factor causing eutrophication of water body, and culture eutrophication has been identified as the primary problem affecting surface water quality globally [1]. Excessive nutrient loading in lakes and ponds may cause turbidity and malodour of the water, while enhanced growth of phytoplankton and other aquatic plants associated deoxygenation can lead to fish kills [2-3]. Therefore, Phosphorus has been established as the nutrient that commonly limits productivity and the phosphorus emission standards are stricter for various waste streams.

Meanwhile, Phosphorus (P) is essential to agricultural and industrial development, which is mined almost commonly from phosphorite or phosphate rock. phosphorus is a nonrenewable resource in this context [4]. Global phosphate reserves are limited and a series of studies reported that the existing phosphate reserves would be depleted in the next 50 to 100 years [5].

Therefore, sustainable phosphorus recovery from waste streams has been paid more and more attention, which can reduce reliance on the finite phosphate resource, relieve the growing demands pressure of phosphorous consumptions, and on the other hand, can also reduce water pollution caused by phosphate-containing waste water discharge.

Struvite crystallization in waste water has shown tremendous potential for development in recovering phosphorus, which can be used as fertilizer in agriculture [6]. As a slow-release fertilizer, struvite is more conducive to crop growth compared to traditional fertilizers. In recent years, there have been many research studies on struvite processes. The phosphorus in waste water is mainly recovered by crystallization of magnesium ammonium phosphate $\left(\mathrm{MgNH}_{4} \mathrm{PO}_{4} \cdot 6 \mathrm{H}_{2} \mathrm{O}, \mathrm{MAP}\right)$ [7-8] and calcium phosphate $\left(\mathrm{Cax}\left(\mathrm{PO}_{4}\right) \mathrm{y}, \mathrm{CP}\right)$ [9-10].

One of the important disadvantages about struvite precipitation is that the crystals formed are uniformly small, ranging from 10 to $100 \mathrm{um}$ [11], which make the struvite crystallization recovery more difficult, and fine crystals are apt to deposit in pipes. From an economic point of view, large crystals should be obtained to facilitate the recovery, transport and commercial operation of the final product [12]. Therefore, In designed struvite precipitation process, larger crystals are preferred.

However, it generally takes a considerable length of time (about days and weeks) to form larger crystals (approximately $400 \mathrm{um}$ ) during the natural struvite crystal growth process [13], and it is necessary to take measures to minimize the running process and make it cost-effective. To 
optimize the crystal formation process and improve phosphorus recovery rate, the batch pilot experiments described in this paper aim to evaluate the effects of seed material, practical size, dosing method, adding amount and $\mathrm{pH}$ on the phosphorus recovery rate and efficiency.

\section{Materials and Methods}

\subsection{Solution Preparation}

Synthetic wastewater solution was formulated to mimic phosphate-containing waste water. Solution was prepared with magnesium chloride hexahydrate $\left(\mathrm{MgCl}_{2} \cdot 6 \mathrm{H}_{2} \mathrm{O}\right)$, ammonium chloride $\left(\mathrm{NH}_{4} \mathrm{Cl}\right)$, and potassium phosphate monobasic $\left(\mathrm{KH}_{2} \mathrm{PO}_{4}\right)$. All chemicals were AR grade. The concentrations of $\mathrm{MgCl}_{2} \cdot 6 \mathrm{H}_{2} \mathrm{O}, \mathrm{NH}_{4} \mathrm{Cl}, \mathrm{KH}_{2} \mathrm{PO}_{4}$ in synthetic wastewater solution are $6.0 \mathrm{mmol} / \mathrm{L}, 15.0 \mathrm{mmol} / \mathrm{L}$ and $5.0 \mathrm{mmol} / \mathrm{L}$ respectively, and the molar ratio of $\mathrm{P}, \mathrm{Mg}$ and $\mathrm{N}$ is 1:1.2:3. The prepared solutions were equilibrated to room temperature in the laboratory four 24 hours before being used.

\subsection{Seeding Materials Preparation}

In the seeded experiments, white quartz sand was chosen as seed materials due to the low solubility under alkaline condition. To evaluate the effects of particle size of seed material, three kinds of quartz sand granularities are used in the experiments, which are 25-50 mesh, 40-70 mesh and 70-140 mesh respectively.

\subsection{Experiment and Sample Analysis}

Seed materials were introduced into the reactor filled with synthetic wastewater solution. Samples were obtained at different time intervals and filtered using $0.45 \mathrm{um}$ membrane. The concentrations of $\mathrm{PO}_{4}{ }^{3-}-\mathrm{P}$ were analyzed according to Standard Methods [14]. Magnetic agitators were used to accelerate reaction rates at low speed and $1.0 \mathrm{M} \mathrm{HCl}$ and $1.0 \mathrm{M}$ $\mathrm{NaOH}$ were used for $\mathrm{pH}$ adjustment during the experiments. The solution $\mathrm{pH}$ was measured using a PHS-3C type $\mathrm{pH}$ meter (Shanghai Leici Instrument Plant, China). All of the experiments were performed at $25^{\circ} \mathrm{C}$ in the laboratory.

\section{Results}

\subsection{Impact of Seed Granularities on Phosphorus Removal Percentage}

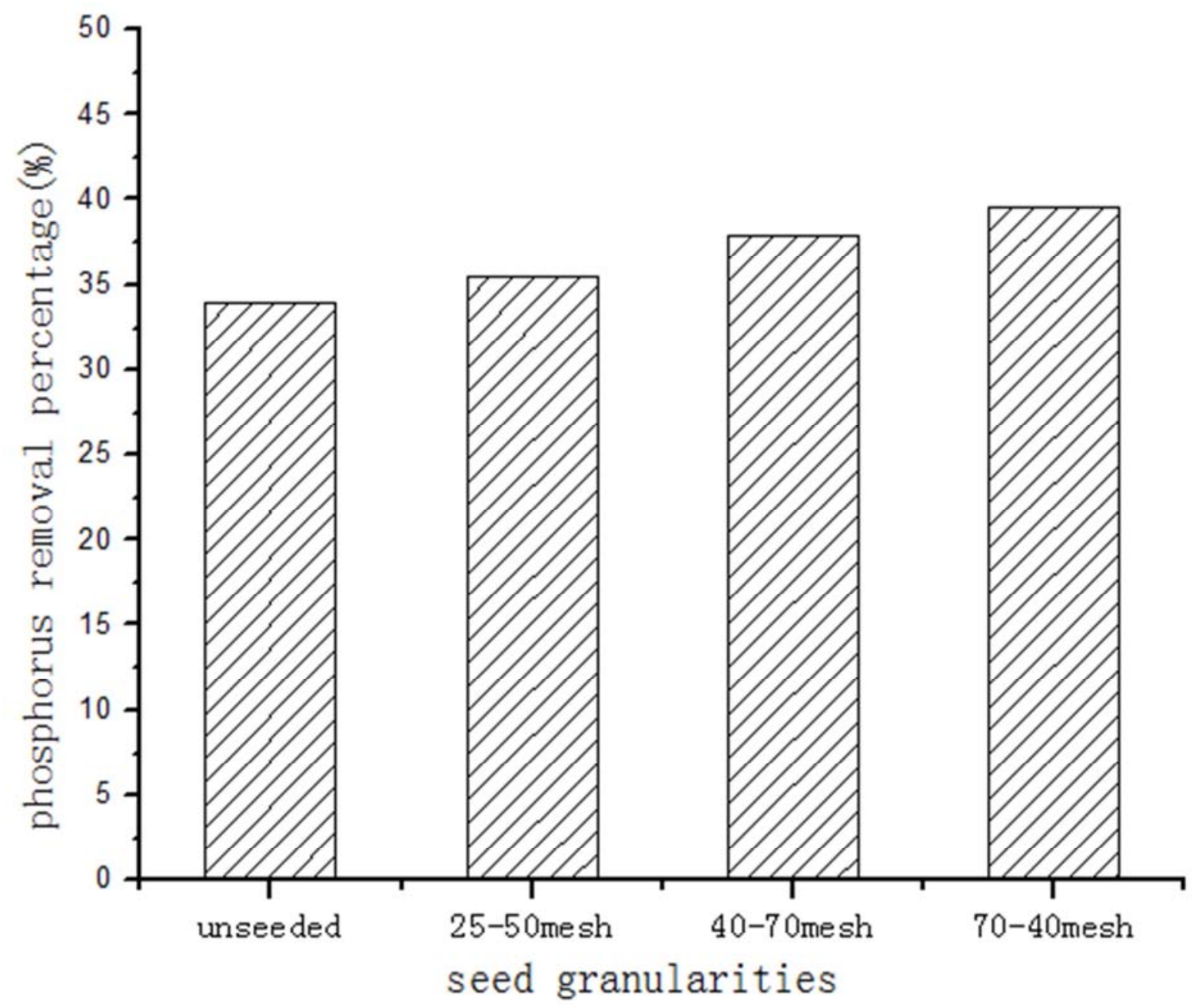

(a) 


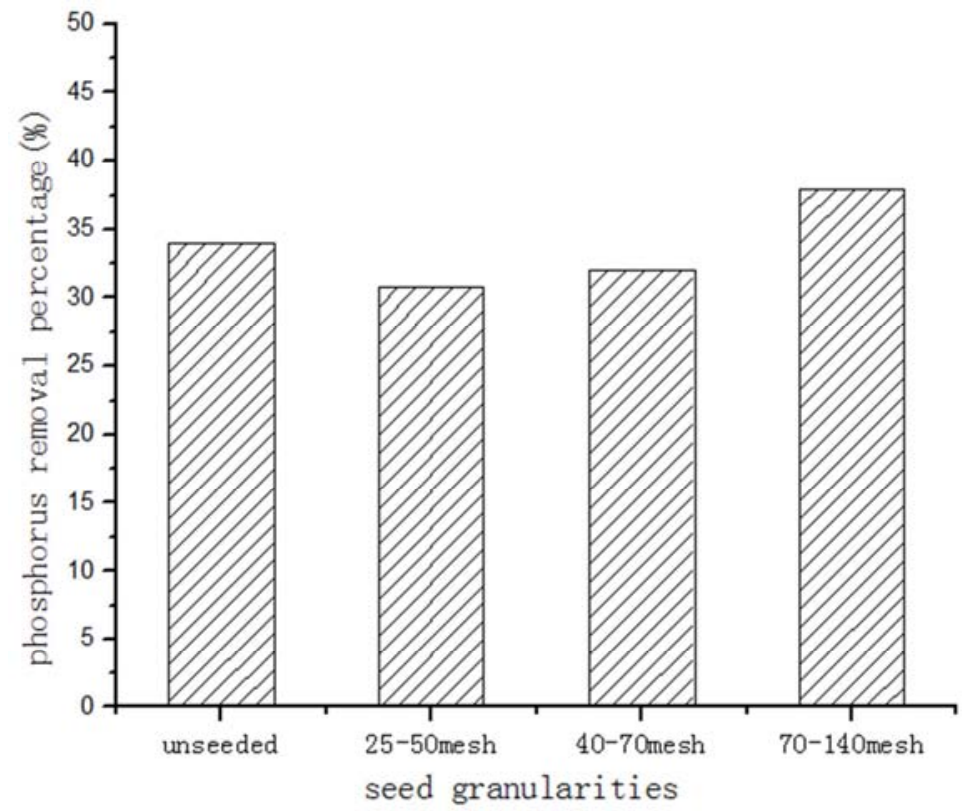

(b)

(a) $1 \mathrm{~g} / \mathrm{L}$ (seed dosing/solution volume) (b) $0.5 \mathrm{~g} / \mathrm{L}$ (seed dosing/solution volume)

Fig. 1. Impact of seed granularities on phosphorus removal percentage ( $p H=7.5$ ).

In order to evaluate the influence of the different particle size seeds on soluble $\mathrm{PO}_{4}$-P removals, experiments undertaken over the range of quartz sand granularities tested were compared to experiments carried out under same conditions of precipitation but without seeds. It can be seen from the Fig. 1a that $\mathrm{PO}_{4}-\mathrm{P}$ removals were $35.6 \%, 39.6 \%$ and $37.9 \%$ with the 25-50mesh, 70-140mesh and 40-70mesh, respectively, where at the same test conditions the soluble $\mathrm{PO}_{4}-\mathrm{P}$ removal without seeds was $34 \%$. The experiment showed that $\mathrm{PO}_{4}-\mathrm{P}$ removal increased distinctly when $1 \mathrm{~g}$ quartz sand seeds were introduced $(\mathrm{pH}=7.5)$. Moreover, the bar graph revealed one obvious peak when $70-140$ mesh seed was added. Fig. $1 \mathrm{~b}$ also showed that $\mathrm{PO}_{4}-\mathrm{P}$ removal reached maximum with $1 \mathrm{~g}$ seed of 70-140 mesh.

With regard to levels of $\mathrm{PO}_{4}-\mathrm{P}$ remaining in solution after $2 \mathrm{~h}$ of experiment, results showed that for similar conditions of precipitation the application of 1 grams seed material works better when compared to crystallization tests with 0.5 grams seed materials. For example, at a seed materials weight of 0.5 grams with three kinds of quartz sand granularities, $\mathrm{PO}_{4}-\mathrm{P}$ removals were $30.76 \%, 37.97 \%$ and $31.95 \%$ respectively, while at a seed materials weight of 1 grams, $\mathrm{PO}_{4}-\mathrm{P}$ removals were $35.5 \%, 39.61$ and $37.92 \%$ accordingly.

\subsection{Impact of pH on Phosphorus Removal Percentage}

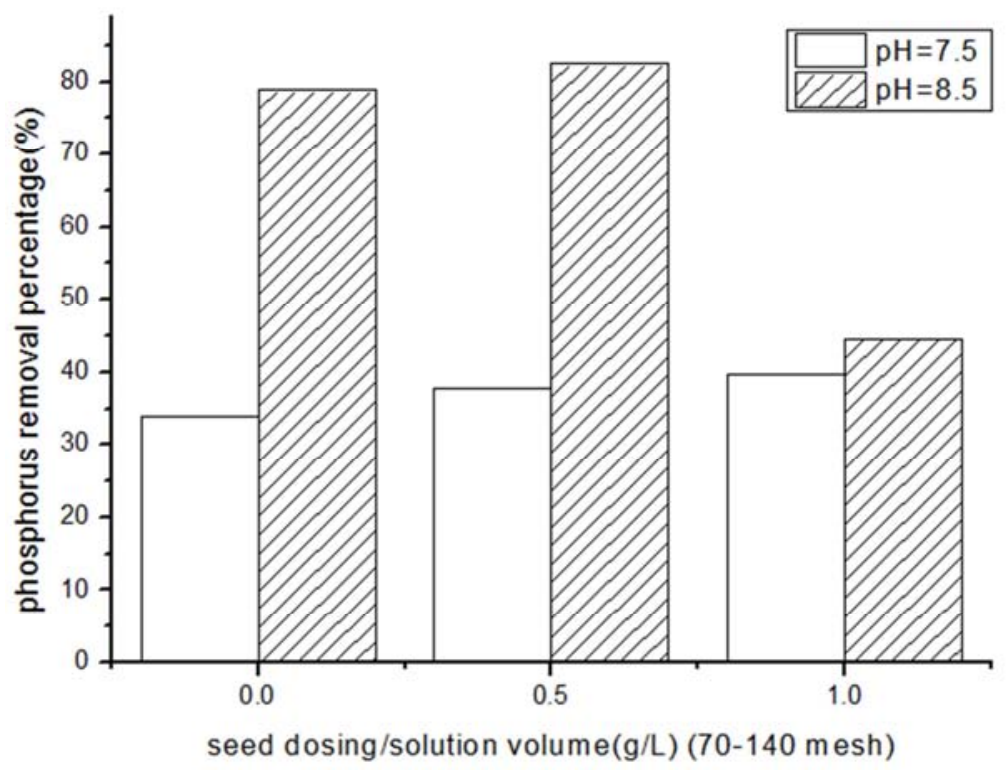

Fig. 2. Impact of pH on phosphorus removal percentage (70-140 mesh). 
To evaluate the comprehensive influence of reaction conditions, three groups of tests were run with $\mathrm{pH}$ set points of 7.5 and 8.5. As shown in Fig. 2, in the first group of tests, when the value of $\mathrm{pH}$ was adjusted from 7.5 to 8.5 , the $\mathrm{PO}_{4}-\mathrm{P}$ removals increased dramatically from $34.00 \%$ to $78.85 \%$ without seeds addition.

In parallel, by introducing the seeds of 70-140 mesh, Fig. 2 showed that the $\mathrm{PO}_{4}-\mathrm{P}$ removals also increased sharply. For the waste water with addition of $1 \mathrm{~g}$ seeds, the obvious increase occurred in the value of $\mathrm{pH} 8.5$ and the corresponding grow rate is $38.22 \%$. Moreover, the more remarkable $\mathrm{PO}_{4}-\mathrm{P}$ removals increase of the waste water doped with $0.5 \mathrm{~g}$ seeds also appeared in the columns, which tripled with the $\mathrm{pH}$ adjusting from 7.5 to 8.5 .

As $\mathrm{pH}$ affected the degree of $\mathrm{PO}_{4}-\mathrm{P}$ removals strongly the influences of $\mathrm{PO}_{4}-\mathrm{P}$ removal speed were further investigated as followed.

\subsection{Impact of Seed Dosing on Phosphorus Removal Percentage}

In order to study the $\mathrm{PO}_{4}-\mathrm{P}$ removals in phosphate-containing waste water, the waste water doped with different contents of seeds was carried out during crystallization experiments. Figure 3 showed the relationship between the amount of seeds (70-140 mesh) and the $\mathrm{PO}_{4}-\mathrm{P}$ removals at $\mathrm{pH}$ set points of 8.5.

As shown in Fig. 3, the $\mathrm{PO}_{4}-\mathrm{P}$ removals increased slightly from $78.85 \%$ to $82.50 \%$ when the seeds content increased from 0 to $0.5 \mathrm{~g}$. However while the seed adding amount continued to rise from $0.5 \mathrm{~g}$ to $1.0 \mathrm{~g}$, the $\mathrm{PO}_{4}-\mathrm{P}$ removals decreased distinctly from $82.5 \%$ to $44.59 \%$. Therefore an apparent peak was observed in the curve of $\mathrm{PO}_{4}-\mathrm{P}$ removals, where the particle size of seed was 70-140 and the $\mathrm{pH}$ was constant at 8.5 , indicated that optimum seed adding amount for struvite precipitation is in the vicinity of $0.5 \mathrm{~g}$.

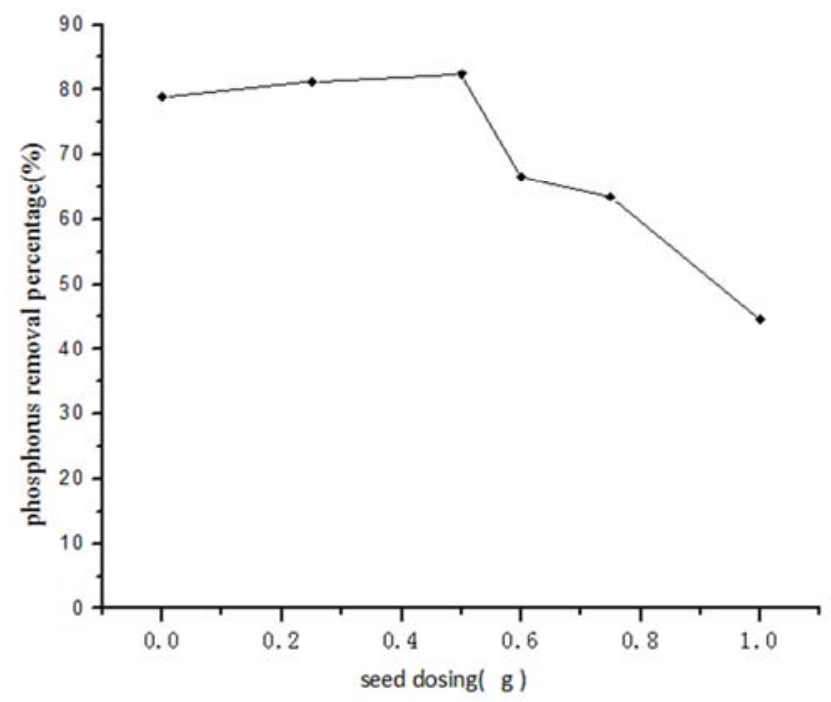

Fig. 3. Impact of seed dosing on phosphorus removal percentage.

\subsection{Impact of Seed Dosing Method on Phosphorus Removal Percentage}

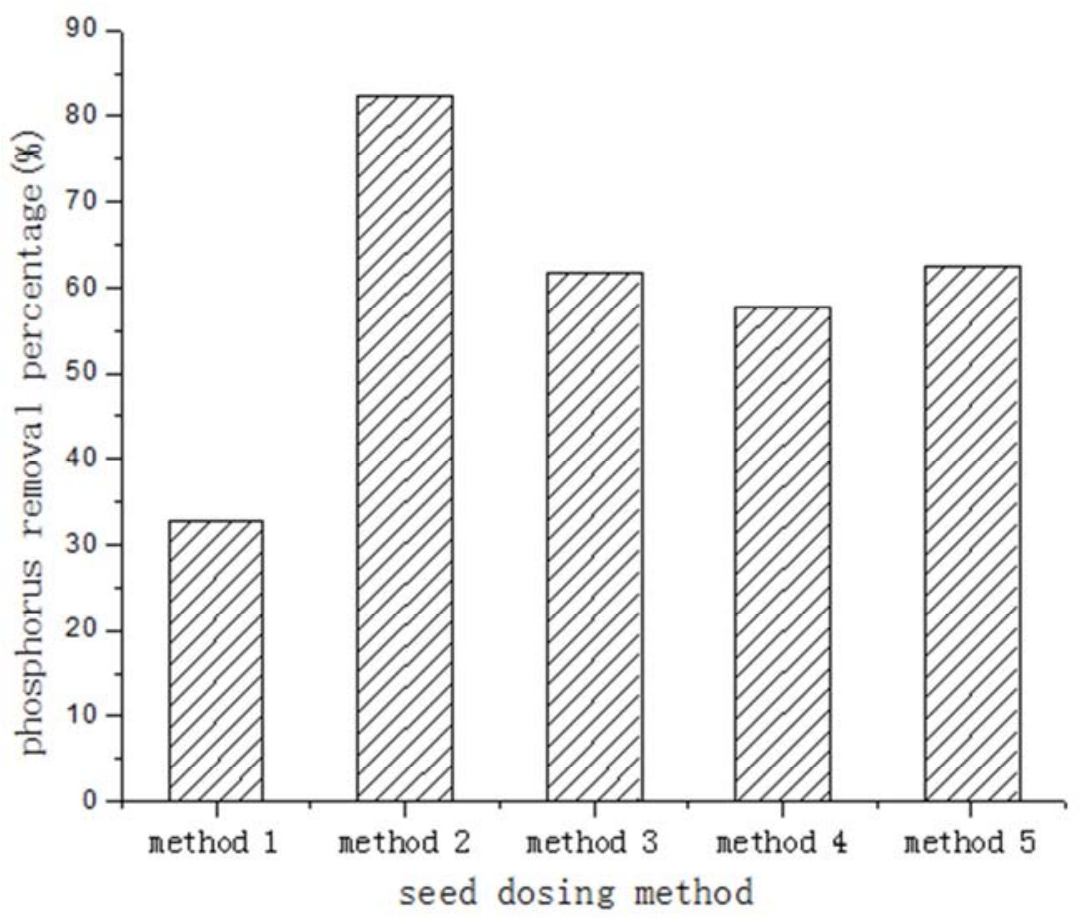

Fig. 4. Impact of seed dosing method on phosphorus removal percentage.

Method 1- multi-stage addition, the addition order of seed: $0.2 \mathrm{~g}-0.15 \mathrm{~g}-0.1 \mathrm{~g}-0.05 \mathrm{~g}$; Method 2- one-stage addition; Method 3- multi-stage addition, the addition order of seed: $0.3 \mathrm{~g}-0.1 \mathrm{~g}-0.1 \mathrm{~g}$; Method 4- multi-stage addition, the addition order of seed: $0.2 \mathrm{~g}-0.2 \mathrm{~g}-0.1 \mathrm{~g}$; Method 5- multi-stage addition, the addition order of seed: $0.4 \mathrm{~g}-0.04 \mathrm{~g}-0.03 \mathrm{~g}-0.03 \mathrm{~g}$. 
In order to study the influences of seeds dosing methods on $\mathrm{PO}_{4}-\mathrm{P}$ removals in waste water, five kinds of seeds dosing methods were carried out with the same adding amount of $0.5 \mathrm{~g}$. The dosing methods of seeds were multi-stage addition except the second dosing method. Fig. 4 presented the effects of seeds dosing methods on $\mathrm{PO}_{4}-\mathrm{P}$ removal efficiency at $\mathrm{pH}$ set points of 8.5.

It can be seen from Fig. 4, the seeding addition methods had a strong effect on $\mathrm{PO}_{4}-\mathrm{P}$ removal efficiency. For instance, $\mathrm{PO}_{4}-\mathrm{P}$ removal efficiency increased slightly from $32.75 \%$ to $61.79 \%, 62.63 \%$ and $82.50 \%$ respectively when initial seed dosing increased gradually from $0.2 \mathrm{~g}$ to $0.3 \mathrm{~g}, 0.4 \mathrm{~g}$ and $0.5 \mathrm{~g}$. The results illustrated that $\mathrm{PO}_{4}-\mathrm{P}$ removal efficiency generally showed an increased trend with the initial seed dosing.

Compared with the first seed dosing method, the initial seed dosing was the same $(0.2 \mathrm{~g})$ but the following seeds dosing was more in the processing of the fourth method. $\mathrm{PO}_{4}$-P removal efficiency ranged from $32.75 \%$ to $57.68 \%$ correspondingly.

\subsection{Impact of Seed on Phosphorus Removal Rate $(\mathrm{pH}=8.5)$}

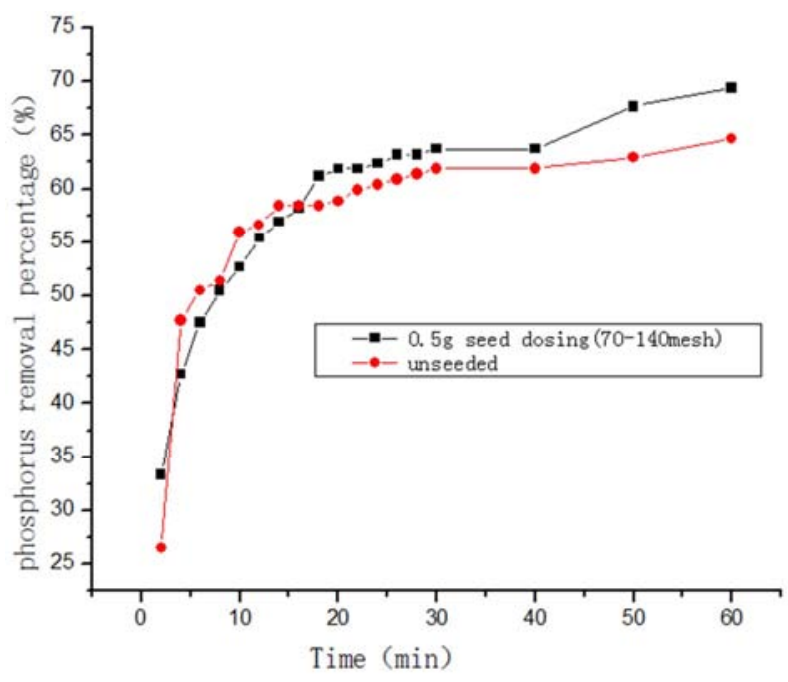

Fig. 5. Impact of seed on phosphorus removal rate $(p H=8.5)$.

To evaluate the effect of seed on $\mathrm{PO}_{4}-\mathrm{P}$ recovery rate samples were obtained at different time intervals during the precipitation experiments. Fig. 5 presented the relationship between the reaction time and $\mathrm{PO}_{4}-\mathrm{P}$ recovery efficiency at $\mathrm{pH}$ set points of 8.5.

From the tests results shown in Fig. 5, reaction time had a clear effect on phosphorus recovery. After a 2 minutes reaction time, without seed, phosphorus recovery efficiency was $26.50 \%$, while it had reached $33.25 \%$ in the seeded test. The results revealed that seeds addition accelerated reaction rates at the initial phase of precipitation experiments. With increased reaction time, higher phosphorus recovery percentages were achieved but no significant difference between the seeded and unseeded experiments until the reaction time of 16 minutes. After 16 minutes of the tests, $\mathrm{PO}_{4}-\mathrm{P}$ recovery efficiencies of seeded experiments were obviously higher than unseeded tests.

Solution with seeding materials achieved 33.55 to $63.66 \%$ phosphorus recovery, while those without showed 26.50 to $61.9 \%$ phosphorous recovery under the first 1 hour of the precipitation experiments. Similarly in the last half hour of tests solution with seeding materials reached $69.40 \%$ while those unseeded only showed $64.7 \%$. The tests results illustrated that seed addition speeded the phosphorus recovery rate to some extent on the whole.

\subsection{Impact of Seed on Phosphorus Removal Rate $(\mathrm{pH}=7.5)$}

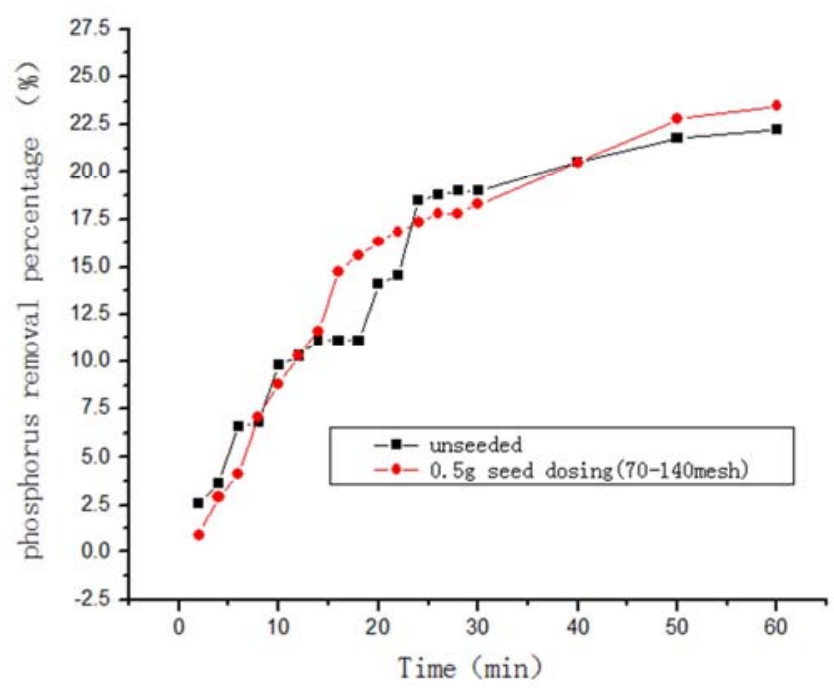

Fig. 6. Impact of seed on phosphorus removal rate $(\mathrm{pH}=7.5)$.

Fig. 6 presented the effect of seed material on phosphorus recovery rate at $\mathrm{pH}$ set points of 7.5. Phosphorus recovery efficiency in solution with seeding materials ranged from $0.85 \%$ to $23.54 \%$ and those without showed $2.59 \%$ to $22.28 \%$. Although phosphorus recovery percentage generally showed an growing trend in reaction time, no significant difference in phosphorus recovery was obtained between seeded and unseeded test when the value of $\mathrm{pH}$ was 7.5.

\section{Discussion}

Struvite is a kind of white water-insoluble crystalline substance, and its general formula is $\mathrm{MgNH}_{4} \mathrm{PO}_{4} \cdot 6 \mathrm{H}_{2} \mathrm{O}[15]$. Struvite produces by the chemical reaction of $\mathrm{Mg}^{2+}, \mathrm{NH}_{4}^{+}$, and $\mathrm{PO}_{4}{ }^{3-}$ in supersaturated solution, and the chemical equation is as follows.

$$
\mathrm{Mg}^{2+}+\mathrm{NH}_{4}{ }^{+}+\mathrm{HPO}_{4}{ }^{2-}+\mathrm{OH}^{-}+6 \mathrm{H}_{2} \mathrm{O} \rightarrow \mathrm{MgNH}_{4} \mathrm{PO}_{4} \cdot 6 \mathrm{H}_{2} \mathrm{O}+\mathrm{H}_{2} \mathrm{O}
$$

From the above equation, It can be seen clearly that continuous consumption of $\mathrm{OH}^{-}$during MAP formation is the main reason for the $\mathrm{PH}$ decrease of the solution, thus keeping a stable alkaline environment during the crystalline process is very important. As shown in Fig. 2, the $\mathrm{PO}_{4}-\mathrm{P}$ removals increased dramatically from $34.00 \%$ at $\mathrm{pH} 7.5$ to $78.85 \%$ at $\mathrm{pH}$ 8.5. Adnan et al [16], Battistoni et al [17] also stated that the operating $\mathrm{pH}$ should be raised up to 8.3 to get more higher 
phosphorus removal.

Moreover, experiment results demonstrated that solution $\mathrm{pH}$ also influenced the growth rate of struvite crystal, when the value of $\mathrm{pH}$ was adjusted from 7.5 to 8.5 , phosphorus recovery efficiency increased dramatically from $2.59 \%$ to $26.50 \%$ in the first 2 minutes of the precipitation tests (Fig. 5, Fig. 6). This result is in accordance with the studies conducted by Momberg and Oellermann, who pointed out that the induction time for struvite precipitation from an anaerobic digester supernatant reduced from days at $\mathrm{pH} 7$ to less than $1 \mathrm{~h}$ at $\mathrm{pH}$ 8.5 [18]. In systems where the $\mathrm{pH}<8$ struvite pre-cipitation is very slow and can spend several days [19]. The reason might be that an increase in solution $\mathrm{pH}$ caused an increase of supersaturation and a resultant increase in the growth rate [20] All above investigations have found that $\mathrm{pH}$ plays an important role during the struvite forming process and solution $\mathrm{pH}$ affects phosphorus recovery percentage as well as phosphorus recovery rate. Kabdasli et al. proposed that $\mathrm{pH}$ might be used as an indicator of struvite nucleation [21].

The process of rystal formation includes two stages: nucleation and growth. Nucleation usually forms spontaneously or can be occurred by the aid of suitable nuclei. As the second stage, crystals keep growing until chemical equilibrium is reached [22]. Tests results revealed that phosphorus recovery efficiency reached a maximum when quartz sand seeds (70-140mesh) were introduced (Fig. 1). It thus can be seen that addition of seed materials to serve as embryo during the struvite precipitation experiments has simulated the formation of nucleation obviously and further increased the phosphorus recovery efficiency.

The previous experiment results implied that the one-stage addition of quartz sand is highly favorable for phosphorus recovery (Fig. 4). The reason might be that nuclei formation before growth could occur on the surface of the seed materials quickly [23]. Nucleation is the first step of the struvite crystallization process [20], so the initial seed dosing palys major role in the process of nucleation, and the follow-up seed addition has little effect. In our previous experiments, results also showed that phosphorus recovery percentage generally showed an increased trend with the initial seed dosing (Fig. 4).

The time lag between the achievement of super saturation and the starting of the crystal nuclei is often termed the induction time [24]. The advantage of infinite induction time is the redissolving of induced crystals in solution due to high-energy consumption from a relatively low driving force [25]. Our experiment results showed that in the first 2 minutes of the precipitation tests, without seed, phosphorus recovery efficiency was $26.50 \%$, while it had reached $33.25 \%$ in the seeded test (Fig. 5). This result may also be attributed to the fact that preliminary additions of seed materials induce surface diffusion of newly born clusters and govern crystallization [26]. Results also showed that After 16 minutes of the tests, phosphorus recovery efficiencies of seeded experiments were obviously higher than unseeded tests. This result implies that as a diffusive medium seeds in the solution enhances crystal growth by allowing layering of newly formed crystallites onto the surface of the seeds [27], and further improves the phosphorus recovery.

\section{Conclusions}

The effects of $\mathrm{pH}$ and seed matirial on MAP crystallization were studied in this paper. Experimental results showed that solution $\mathrm{pH}$ was one of the most important factor which effected phosphorus recovery percentage and rate during the struvite forming process. When the value of $\mathrm{pH}$ was adjusted from 7.5 to 8.5 , phosphorus recovery percentage increased dramatically from $2.59 \%$ to $26.50 \%$ in the first 2 minutes of the precipitation tests and from $34.00 \%$ to $78.85 \%$ at the end of experiments respectively.

Addition of seed materials during the struvite precipitation experiments increased the phosphorus recovery efficiency to an extent and these seed particles which range in size from 70 to 140 meshes achieved a maximum effect in this experiment. Moreover, optimum seed adding amount (70-140 mesh) for struvite precipitation was in the vicinity of $0.5 \mathrm{~g}$ (solution $\mathrm{pH}=8.5$ ). Seeds dosing methods studies proved that the one-stage addition of quartz sand was higher favorable for phosphorus recovery than multi-stage addition and phosphorus recovery percentage generally showed an increased trend with the initial seed dosing. In the first 2 minutes of the precipitation tests, seeded and unseeded phosphorus recovery percentages were $33.25 \%$ and $26.50 \%$ respectively. After 16 minutes of the tests, phosphorus recovery efficiencies of seeded experiments were obviously higher than those unseeded. The tests results illustrated that seed addition speeded the phosphorus recovery rate to some extent on the whole.

\section{Acknowledgements}

This study has been financially supported by the project of Zhejiang Nature Science Foundation (LY12E08001).

\section{References}

[1] Liu X, Hu Z, Wang J, Wen G. Effect of hydraulic retention time and seed material on phosphorus recovery and crystal size from urine in an air-agitated reactor. Water Sci Technol. 2014; 69 (7): 1462-8.

[2] Conley DJ, Paerl HW, Howarth RW, Boesch DF, Seitzinger SP, Havens, KE, Lancelot C, Likens GE. Controlling eutrophication by reducing both nitrogen and phosphorus. Science. 2009; 323: 1014-1015.

[3] Paerl HW, Huisman J. Blooms like it hot. Science. 2008; 320 (5872): 57-58.

[4] Lin J, Chen N, Pan Y. Arsenic speciation in newberyite $\left(\mathrm{MgHPO}_{4} \cdot 3 \mathrm{H}_{2} \mathrm{O}\right)$ determined by synchrotron X-ray absorption and electron paramagnetic resonance spectroscopies: implications for the fate of arsenic in green fertilizers. Environmental science \& technology. 2014; 48 (12): 6938-46.

[5] Cordell D, Drangert J-O, White S. The story of phosphorus: Global food security and food for thought. Global Environmental Change. 2009; 19 (2): 292-305. 
[6] Kruk DJ, Elektorowicz M, Oleszkiewicz JA. Struvite precipitation and phosphorus removal using magnesium sacrificial anode. Chemosphere. 2014; 101: 28-33.

[7] Liu Y, Kwag JH, Kim JH, Ra C. Recovery of nitrogen and phosphorus by struvite crystallization from swine wastewater. Desalination. 2011; 277:364-369.

[8] Capdevielle A, Sykorova E, Biscans B, Beline F, Daumer ML. Optimization of struvite precipitation in synthetic biologically treated swine wastewater-determination of the optimal process parameters. J. Hazard. Mater. 2013; 244: 357-369.

[9] Song YH, Weidler PG, Berg U, Nuesch R, Donnert D.. Calcite-seeded crystallization of calcium phosphate for phosphorus recovery. Chemosphere.2006; 63: 236-243.

[10] Bauer PJ, Szogi AA, Vanotti MB. Agronomic effectiveness of calcium phosphate recovered from liquid swine manure. Agron. J. 2007; 99: 1352-1356.

[11] Wang J, Burken JG, Zhang XQ. Effect of Seeding Materials and Mixing Strength on Struvite Precipitation. Water Environment Research. 2006; 78 (2): 125-132.

[12] Pastor L, Mangin D, Barat R. A pilot-scale study of struvite precipitation in a stirred tank reactor: conditions influencing the process. Bioresour. Technol. 2008; 99 (14): 6285-6291.

[13] Durrant, AE, Scrimshaw, MD, Stratful I, Lester JN. Review of the Feasibility of Recovering Phosphate from Wastewater for Use as a Raw Material by the Phosphate Industry. Environ Technol.1999; 20 (7): 749.

[14] NEPA. Water and waste water monitoring analysis method [M]. Beijing: China Environmental Science Press, 2002.

[15] Doyle JD, Parsons SA. Struvite formation, control and recovery. Water Research.2002; 36: 3925-3940.

[16] Adnan, A., Koch, F. A., Mavinic, D. S., 2003. Pilot-scale study of phosphorus recovery through struvite crystallisation-II: applying in-reactor supersaturation ratio as a process control parameter. J. Environ. Eng. Sci. 2, 473-483.

[17] Battistoni P, Angelis A, Pavan P. Phosphorus removal from a real anaerobic supernatant by struvite crystallization. Water Res. 2001; 35: 2161-2178.

[18] Momberg GA, Oellermann RA. The removal of phos-phate by hydroxyapatite and struvite crystallisation in South Africa. Water Sci Technol. 1992; 26: 987-96.

[19] Battistoni P, Fava G, Pavan P, Musacco A, Cecchi F. Phosphate removal in anaerobic liquors by struvite crystallisation without addition of chemicals: preliminary results. Water Res 1997; 31 : 2925-9.

[20] Le Corre KS, Jones EV, Hobbs P, Parsons SA. Phosphorus recovery from wastewater by struvite crystallization: a review. Crit. Rev. Environ. Sci. Technol. 2009; 39: 433-477.

[21] Kabdasli I, Parsons SA, Tunay O. Effect of major ions on struvite crystallization. In: Proceedings of the International Conference on Struvite: Its Role in Phosphorus Recovery and Reuse. Cranfield, UK. 2004.

[22] Rahman MM, Salleh MAM, Rashid U, Ahsan A, Hossain MM, $\mathrm{Ra}$ CS. Production of slow release crystal fertilizer from wastewaters through struvite crystallization - A review. Arabian Journal of Chemistry. 2014; 7 (1): 139-55.

[23] Rahaman MS, Ellis N, Mavinic DS. Effects of various process parameters on struvite precipitation kinetics and subsequent determination of rate constants. Water Sci. Technol. 2008; 57 (5): 647-654

[24] Mullin JW. Crystallization. Ipswich: Butterworth-Heinnemann. UK.1993.

[25] Ali MI, Schneider PA. Crystallization of struvite from metastable region with different types of seed crystal. J. Non-Equilib. Thermodyn. 2005; 30: 95-111.

[26] Munch EV, Barr K, Controlled struvite crystallization for removing phosphorus from anaerobic digester side-streams. Water Res. 2001; 35: 151.

[27] Ali MI, Schneider PA. A fed-batch design approach of struvite system in controlled supersaturation. Chem. Eng. Sci. 61, 3951-3961. 